\title{
Cooperação intergovernamental na política de mobilidade urbana: o caso do Consórcio Intermunicipal do $A B C$
}

\author{
Intergovernmental cooperation in the urban mobility policy: the case of the \\ $A B C$ Intermunicipal Consortium
}

Eduardo Scorzoni Ré, Vanessa Elias de Oliveira

Universidade Federal do ABC, Santo André, SP, Brasil

\section{Resumo}

Este artigo apresenta as relações intergovernamentais coordenadas pelo Consórcio Intermunicipal do Grande ABC para a política de mobilidade da região do ABC paulista, identificando os papéis de atores governamentais e não estatais, particularmente o próprio consórcio, em seu desenvolvimento. A questão principal que procura responder é: como o Consórcio Intermunicipal articulou as forças para promover o desenvolvimento da política de mobilidade urbana na região? A pesquisa foi realizada através da análise das atas do Grupo de Trabalho Mobilidade Urbana e as atas das Assembleias de Prefeitos de 2010 a 2013. Além disso, os atores-chave na política de mobilidade urbana regional foram entrevistados. 0 artigo demonstra como as ações municipais iniciais - marcadas pelo desenvolvimento de projetos específicos e com pouca atenção "regional" - foram modificadas como consequência da institucionalização do Grupo de Trabalho Mobilidade Urbana. Tal conquista se deve à capacidade do Consórcio para promover ações de cooperação e regionalmente comuns, que levam em consideração as características institucionais de cada município. Além disso, o artigo mostra que o Consórcio tornou-se um articulador regional, ante os governos estadual e federal, o que foi crucial para a obtenção de recursos para vários projetos, especialmente os relativos à política de mobilidade urbana.

Palavras-chave: Municípios. Cooperação intergovernamental. Regiões metropolitanas. Política de mobilidade urbana. Consórcio Intermunicipal do Grande ABC.

\section{Abstract}

This article presents the intergovernmental relations coordinated by the Grande ABC Intermunicipal Consortium for the mobility policy of the $A B C$ region in the state of São Paulo, identifying the roles of governmental and non-governmental actors, particularly the consortium itself, in its development. The main investigated question was: how has this Intermunicipal Consortium articulated forces to promote the development of the urban mobility policy in the region? A qualitative research was carried out through the analysis of the minutes of the "Urban Mobility" Working Group and of the Mayors Assemblies held from 2010 to 2013. Other relevant documents produced by the Consortium were also considered. In addition to this, key actors in the regional urban mobility policy were interviewed. The article demonstrates how the initial municipal actions - marked by the development of specific projects and little 'regional' attention - were modified as a consequence of the

ESR é formado em Administração Pública, mestre em Planejamento e Gestão do Território, e-mail: eduardo_scorzoni@yahoo.com.br VEO é formada em Ciências Sociais, doutora em Ciência Política, e-mail: vanessa.oliveira@ufabc.edu.br 
institutionalization of the "Urban Mobility" Working Group. Such an achievement was due to the ability of the Consortium to promote cooperative and regionally joint actions that took into account the institutional constraints of each municipality. Moreover, the article shows that the Consortium became a regional articulator before the state and federal governments, what was crucial for obtaining resources for various projects, especially the ones concerning urban mobility policy.

Keywords: Municipalities. Intergovernmental cooperation. Metropolitan areas. Urban mobility policy. "Grande ABC" Intermunicipal Consortium.

\section{Introdução}

As regiões metropolitanas no Brasil têm sido tema de debates sobre os desafios de constituir políticas públicas de forma cooperada entre os entes federativos e entre estes e organizações não governamentais. Os municípios dessas regiões, marcadas pela exacerbação de problemas como poluição, degradação ambiental, violência e obstáculos para a mobilidade urbana, estão empenhados em buscar alternativas para as adversidades geradas pelas deseconomias de escala e pela autonomia federativa, e encontram na articulação regional mecanismos para aumentar o poder de barganha frente aos outros entes federativos, além de conseguirem desenvolver políticas públicas com maior eficiência e eficácia.

0 aumento das articulações entre os entes federativos tem se mostrado uma forma profícua de consolidar políticas públicas de impacto regional. Os instrumentos utilizados para a cooperação são a constituição de parcerias, consórcios, agências de desenvolvimento, dentre outros. Os resultados obtidos por esses arranjos, em termos de produção de políticas públicas, variam conforme a sua consolidação institucional, força perante outros atores envolvidos (governamentais ou não governamentais) e, ainda, o peso que conseguirão garantir para que seus distintos membros possam influenciar o desenho final da política (Abrucio et al., 2010).

No presente artigo, analisamos a política de mobilidade urbana no $\mathrm{ABC}$ paulista a partir do mapeamento dos atores e suas interações no Consórcio Intermunicipal do Grande $\mathrm{ABC}$, para demonstrar, em primeiro lugar, os conflitos e as dificuldades encontradas na promoção da política e, ao mesmo tempo, os caminhos encontrados pelos municípios para o desenvolvimento da cooperação regional; em segundo lugar, como um processo de planejamento que leve em consideração a participação dos distintos atores que estão ligados à política tem se mostrado uma alternativa exitosa para a execução de políticas públicas de abrangência metropolitana (Klink, 2005).

A questão principal que o trabalho pretende responder é: como o Consórcio Intermunicipal Grande ABC tem articulado as forças promotoras do desenvolvimento da política de mobilidade urbana na região? Mais especificamente, procuraremos compreender se o consórcio "empoderou" os municípios frente aos governos estadual e federal na construção da política regional de mobilidade urbana e, ainda, de que forma a instituição equilibrou as diferenças de necessidades e de capacidade institucional entre os municípios.

Para tal, foram analisadas as atas das reuniões do Grupo de Trabalho Mobilidade Urbana e, também, as atas das reuniões da Assembleia dos Prefeitos do Consórcio Intermunicipal Grande $\mathrm{ABC}$ no período 2010-2013. Além das atas, foram analisados documentos como o Planejamento Estratégico, ofícios enviados e recebidos pelo Consórcio, tanto de instituições públicas quanto privadas, e documentos de planejamento da instituição. Somado a isso, foram realizadas entrevistas ${ }^{1}$ com atores-chave da política de mobilidade urbana regional. As entrevistas objetivaram elucidar questões relacionadas à cooperação intermunicipal, às relações interfederativas e relações com entidades não governamentais que não estão registradas nos documentos do Consórcio. Portanto, trata-se de uma pesquisa qualitativa, baseada em análise de documentos e em entrevistas.

0 artigo estrutura-se da seguinte maneira: na próxima seção contextualizamos teoricamente

\footnotetext{
${ }^{1}$ Foram entrevistadas 8 (oito) pessoas relacionadas à política de mobilidade do ABC paulista, como coordenadores e ex-presidentes do Consórcio, secretários municipais e assessores. A pedido dos entrevistados, os nomes foram mantidos no anonimato e os caracterizamos nesse trabalho por uma numeração.
} 
nosso objeto, a partir das discussões sobre regiões metropolitanas e cooperação intergovernamental no federalismo brasileiro, apresentando a região do $\mathrm{ABC}$ paulista. A seguir, tratamos da realidade dos consórcios intermunicipais no Brasil, com destaque para o caso do Consórcio Intermunicipal Grande ABC. A partir disso, analisamos a sua atuação na promoção da política regional de mobilidade urbana, demonstrando o papel dos diferentes atores nesse processo de cooperação intergovernamental. Por fim, concluímos com algumas considerações sobre como o caso estudado é útil para a compreensão dos mecanismos estabelecidos pelos atores para promover a cooperação, num contexto de federalismo, com municípios autônomos, sem incentivos claros para a coordenação federativa como o brasileiro.

\section{Regiões metropolitanas e cooperação intergovernamental no federalismo brasileiro}

O Censo Demográfico de 1940 revela que o grau de urbanização brasileira era, à época, de pouco mais de $20 \%$. A partir da década de 1950 , o espaço urbano ganha importância na medida em que passa a ser o lócus onde a força do sistema capitalista visualiza um meio profícuo para sua reprodução, tornando-se o local privilegiado dos meios produtivos.

O sistema de substituição de importações transforma o meio urbano, fazendo com que os problemas surgidos pelas grandes aglomerações entrem na agenda federal. Conjuga-se a esse período histórico o momento político autoritário brasileiro, no qual a preocupação macroeconômica torna-se prevalecente em relação às questões intraurbanas. Os dados sobre urbanização demonstram a velocidade e a intensidade com que a população brasileira migra para as cidades em busca de trabalho e melhores condições de vida, e entre as décadas de 1960 e 1970 a população urbana supera o número de moradores das regiões rurais.

Para Santos (1993), as mudanças urbanas e demográficas ensejaram uma urbanização aglomerada, concentrada, desembocando no patamar da metropolização. O espraiamento da ocupação e do crescimento urbano deixa de ver os limites políticos entre os municípios, e o crescimento horizontal transforma-se no fenômeno denominado conurbação.

A metropolização completou-se, segundo Lacerda et al. (2000), por meio do crescimento da conurbação de núcleos urbanos periféricos ao município central, onde se encontravam as mais importantes atividades econômicas, culturais e de infraestrutura urbana. Do lado da periferia, sua ocupação caracterizou-se pela precariedade da infraestrutura habitacional, viária, do sistema de saneamento básico, além de problemas ambientais e ocupações em áreas protegidas.

A modificação da estrutura urbana e social brasileira ensejava, por parte do governo federal, mudanças na política de tratamento da questão urbana e, principalmente, da questão metropolitana. A partir dessa constatação é que surge, na década de 1970, a normatização e legislação específica para criação de regiões metropolitanas (RMs). A Lei Complementar n. 14, de 1973 (Brasil, 1973), institucionalizou a criação das primeiras oito regiões metropolitanas (São Paulo, Belo Horizonte, Porto Alegre, Recife, Salvador, Belém, Fortaleza e Curitiba), seguida pela criação da RM do Rio de Janeiro, por meio da Lei Complementar n. 20 de 1974 (Brasil, 1974).

A institucionalização "de cima para baixo", sem articulação com os entes e/ou a criação de mecanismos de cooperação, não favoreceu a constituição de relações intergovernamentais para a governança metropolitana, cenário este que se manteve mesmo com a democratização (Souza, 2003). A Constituição Federal de 1988 passou a outorgar o poder de criação das RMs para a esfera estadual (art. 25, parágrafo $3^{\circ}$ ), que assume o poder de criar as aglomerações urbanas e as microrregiões, mas não se fizeram avanços posteriores na regulamentação da matéria, o que acabou gerando um vácuo institucional (Brasil, 1988).

Somente mais recentemente o governo federal retomou seu olhar para as regiões metropolitanas, concentrando iniciativas voltadas para a questão na Presidência da República, por meio da Secretaria de Relações Institucionais (SRI). Ademais, apesar da recente aprovação do Estatuto da Metrópole, Lei n. 13.089 (Brasil, 2015), não são poucos os obstáculos à cooperação metropolitana. Conforme Fernandes \& Araújo (2015), ainda que o Estatuto proponha diretrizes para a governança federativa, dentre elas um processo permanente de planejamento e de tomada de decisão para o desenvolvimento urbano e demais políticas públicas de interesse regional, foi vetada a proposta de criação de um Fundo Nacional de Desenvolvimento Urbano Integrado (FNDUI), o que pode evidenciar a não priorização do tema pelo governo federal (Fernandes \& Araújo, 2015, p. 306-307). 


\section{A região do Grande $A B C$ no} estado de São Paulo

Os municípios do ABC paulista (Santo André, São Bernardo do Campo, São Caetano do Sul, Diadema, Mauá, Ribeirão Pires e Rio Grande da Serra) possuem relevante importância histórica, social e econômica, pois se caracterizam pelo forte desenvolvimento industrial baseado no setor automobilístico, de petróleo, químico, entre outros, além de ser uma notável região de forte coesão sindical e com presença de importantes organizações sociais.

Por apresentar um importante parque industrial, a região do $\mathrm{ABC}$ foi atingida de maneira intensa pela crise econômica dos anos 1980, conhecida como "década perdida", decorrente das altas taxas de inflação e de baixo crescimento econômico. A partir de então, a região começou a perder participação no contexto nacional devido à elevação do desemprego, desaceleração do crescimento industrial e aumento da informalidade do emprego. É nesse contexto que os municípios do $\mathrm{ABC}$ se unem para iniciar um movimento de cooperação intermunicipal, visando combater os problemas sociais e alavancar novamente a economia regional.

Impactados pelo modelo de urbanização das metrópoles brasileiras, os municípios da região vêm buscando desenvolver políticas públicas integradas para diminuir as consequências da urbanização concentradora e excludente.

\section{Os consórcios intermunicipais e o caso do Consórcio Intermunicipal do ABC}

Podemos compreender o conceito de consórcio como um arranjo de caráter voluntário entre os entes participantes, que, ao contrário das regiões metropolitanas, que surgiram de cima para baixo, se associam de forma compulsória (Spink et al., 2009); como uma organização que resulta do arranjo de cooperação entre atores políticos de municípios que resolvem cooperar entre si na busca de resolução de problemas (Caldas, 2007); ou, ainda, como uma forma de cooperação entre os municípios destinada a solucionar problemas e obter resultados conjuntos de natureza superior às capacidades política, financeira e operacional individual de seus integrantes (Cruz \& Araújo, 2011).
Dados sobre as articulações interinstitucionais da Pesquisa de Informações Básicas Municipais do IBGE (2015), que analisou as associações pactuadas entre os entes federativos no ano de 2015, mostram que 3.691 dos 5.570 municípios do país (66,3\%) participavam de algum tipo de consórcio público. Além disso, 351 (6,3\%) participavam de consórcios relacionados à política pública de transporte.

0 alto número de municípios que participam de alguma forma de cooperação indica a aderência às possibilidades colocadas pelo sistema federativo brasileiro. Essa aderência aos arranjos de articulação institucional ocorre por diversos motivos e dependem das características demográficas, sociais, econômicas e ambientais das regiões onde os municípios estão inseridos.

\section{Consórcio Intermunicipal do Grande ABC}

A cooperação regional no ABC mostra-se como um caso emblemático, pois conseguiu superar parte das dificuldades impostas pela dinâmica federativa brasileira, que não oferece grandes incentivos à associação dos agentes governamentais, especialmente no contexto das regiões metropolitanas, acumulando um histórico de cooperação regional.

O Consórcio Intermunicipal do Grande ABC, criado no ano de 1990, foi a primeira instituição de cooperação formada na região e surge como importante agente institucional que reúne as sete cidades do Grande ABC, com o objetivo de promover e implementar diretrizes de planejamento, articulação e definição de ações de caráter regional (Abrucio et al., 2010).

As ações do Consórcio são constituídas em diversos eixos de trabalho, também denominados como Eixos Estruturantes, compostos pelos seguintes temas: Infraestrutura; Segurança Pública; Saúde; Assistência, Inclusão Social e Direitos Humanos; Educação, Cultura e Esportes; Desenvolvimento Econômico Regional; Desenvolvimento Urbano e Gestão Ambiental; Institucional. 0 Consórcio atua, dentro desses temas, em grupos de trabalhos (GTs) para estudos e análises em diversas áreas, a fim de criar quadros de diagnósticos e propostas de ações.

0 foco do presente trabalho é a área de mobilidade urbana, caracterizada no consórcio pelo eixo Infraestrutura. Esse GT levantou diagnóstico e formulou propostas para o Plano de Mobilidade Regional, principal 
instrumento regional de diretrizes e de ações para a política de mobilidade da região do ABC.

\section{O papel do consórcio Intermunicipal do Grande $A B C$ para a política regional de mobilidade urbana}

Dentre as finalidades do eixo Infraestrutura, um dos eixos de atuação do Consórcio, aquelas que se relacionam com o tema da mobilidade são: 1 . Integrar a região aos principais sistemas viários da Região Metropolitana de São Paulo aos portos e aeroportos; 2. Aprimorar os sistemas logísticos de transporte rodoviário e ferroviário de cargas; 3 . Aprimorar o transporte coletivo urbano municipal e metropolitano; e 4. Desenvolver plano regional de acessibilidade, conforme Consórcio Intermunicipal do Grande ABC (2014).

Vinculado a este eixo encontra-se o GT Mobilidade, de caráter técnico e envolve profissionais de diversas áreas dos municípios (como engenheiros, arquitetos e urbanistas), que estudam e propõem ações específicas para uma demanda ou diretriz acordada pelos entes. Para entender a forma como o Consórcio estabelece relações com outros entes federativos e também com atores e instituições não governamentais para o tema de mobilidade urbana, foram analisadas as atas das reuniões da Assembleia Geral dos prefeitos.

\section{Atores e instituições}

As ações desenvolvidas dentro do Consórcio relacionadas à mobilidade urbana são construídas e determinadas por um conjunto de atores e de instituições que estão inseridos na articulação regional desta política pública. A separação entre atores ou instituições governamentais e não governamentais para a análise das ações específicas considera as diferenças das dinâmicas do Estado e de organizações fora dele. Essa metodologia está baseada no trabalho de Cruz (2010), que analisa os condicionantes que influem no processo de construção da política de transportes coletivos na região metropolitana de São Paulo.

Para a melhor definição do papel de cada agente, no Quadro 1 estão listados os atores e instituições e suas áreas de atuação.

Considerando a participação desses agentes, analisaremos a seguir a forma como se realiza a cooperação entre os setes municípios do $\mathrm{ABC}$ dentro

Quadro 1 - Atores e instituições atuantes nas ações de mobilidade urbana na região do ABC

\begin{tabular}{|c|c|c|}
\hline Atores & Instiłuição & Atuação \\
\hline \multirow{2}{*}{ União } & Ministério do Planejamento Orçamento e Gestão & $\begin{array}{l}\text { Análise dos projetos do Plano de Mobilidade Regional. } \\
\text { Financiamento de projetos por meio do PAC Mobilidade Urbana. }\end{array}$ \\
\hline & Ministério das Cidades & $\begin{array}{l}\text { Planejamento integrado entre políticas públicas; normatização e diretrizes para } \\
\text { organização das cidades. }\end{array}$ \\
\hline \multirow{5}{*}{ Estado } & EMPLASA & Produção técnica de dados e informações em âmbito metropolitano. \\
\hline & STM: PITU & $\begin{array}{l}\text { Planejamento metropolitano de transportes (investimentos em expansão e requalifi- } \\
\text { cação). }\end{array}$ \\
\hline & EMTU & Gerir as linhas de ônibus intermunicipais na RM. \\
\hline & DERSA & Atuação na construção do Rodoanel. \\
\hline & ARTESP & Atuação na fiscalização de concessões de rodovias da Região do ABC. \\
\hline Municipios & Secretarias relacionadas ao tema de mobilidade/transporte & Cessão de quadros técnicos na articulação intermunicipal. \\
\hline Empresas & Multinacionais & Direcionamento de ações e de investimento da política de mobilidade urbana. \\
\hline \multirow{3}{*}{$\begin{array}{l}\text { Sociedade civil } \\
\text { organizada }\end{array}$} & Usuários & Manifestações, Ciclistas. \\
\hline & Sindicatos & $\begin{array}{l}\text { Reajuste da tarifa de táxi; reajuste tarifário das empresas de transporte coletivo; } \\
\text { regulamentação da profissão de motofrete. }\end{array}$ \\
\hline & Federação Paulista de Ciclismo & Inclusão na agenda sobre a criação da ciclofaixa na região. \\
\hline Outros & ANTP & Troca de experiências e informações com o Consórcio. \\
\hline
\end{tabular}

Fonte: Elaboração própria (2014). 
do Consórcio e como esta instituição se coloca perante os governos estadual e federal na busca de ações coordenadas para a política de mobilidade urbana. Além disso, analisaremos a participação de outros organismos no direcionamento das ações para a mobilidade urbana na região do $\mathrm{ABC}$.

\section{A construção da cooperação} para a mobilidade no Consórcio Intermunicipal do Grande ABC

0 conceito de mobilidade urbana vem se modificando nos últimos anos, na medida em que deixa de tratar de maneira fragmentada questões relativas à locomoção - e basicamente a circulação de veículos -, para debruçar-se sobre o deslocamento de pessoas e bens dentro do espaço das cidades, mediante utilização de veículos, de vias públicas e da infraestrutura disponível. Além disso, o conceito de mobilidade urbana tem se apoiado em quatro pilares: (1) Integração do planejamento de transporte com o planejamento do uso do solo; (2) Melhoria do transporte público de passageiros; (3) Estímulo ao transporte não motorizado; e (4) Uso racional do automóvel (TCU, 2010). Esses conceitos estão baseados nas diretrizes da Política Nacional de Mobilidade Urbana, por meio da Lei n. 12.587 (Brasil, 2012), que tem como objetivo proporcionar aos cidadãos o acesso universal à cidade, melhorando a acessibilidade e mobilidade de pessoas e cargas no território ${ }^{2}$. São diretrizes norteadoras como essas que o Consórcio vem desenvolvendo nos últimos anos ações e planos para melhorar a mobilidade urbana no $\mathrm{ABC}$, por meio de articulação entre os sete municípios e os governos federal e estadual.

A presente pesquisa voltou-se para o entendimento da construção de um plano de mobilidade de âmbito regional sem, no entanto, se expandir para o estudo da articulação do GT Mobilidade com outros grupos de trabalho dentro do Consórcio - como, por exemplo, o de Planejamento Urbano. Vale salientar que o GT Mobilidade possuía como uma de suas diretrizes a preocupação em atuar considerando as ações e políticas de uso e ocupação do solo, porém, à época, não houve real incorporação desses temas ao debate sobre mobilidade urbana.

\footnotetext{
${ }^{2}$ Para uma compreensão atualizada e mais técnica sobre a questão da mobilidade urbana em regiões metropolitanas, ver Cunha et al. (2013) e Pero \& Stefanelli (2015).
}

A partir dos anos 2000, o debate sobre a questão do transporte e da mobilidade na região se desenvolve no sentido de gerar maior integração entre os municípios. Tendo em vista os problemas acarretados pelas deseconomias de escala em uma região como o ABC paulista, e pela inexistência de integração em diversos serviços de trânsito, os municípios começam a discutir temas relacionados à articulação conjunta de soluções para as demandas existentes. Até o ano de 2010, muitas das questões discutidas pelo Consórcio estavam centradas em pontos específicos de transporte e de mobilidade, como os relacionados à criação unilateral de linhas pela EMTU, que concorriam com os sistemas municipais.

Com o acúmulo de informações sobre a situação de diversas políticas e o desenvolvimento de projetos para implantação de ações específicas, e cientes da necessidade de diálogo com o governo estadual e com o governo federal para o desenvolvimento de programas e projetos na região do $\mathrm{ABC}$, os sete municípios definiram em 2011 uma relação de reivindicações prioritárias para serem negociadas com cada um dos entes federativos.

De acordo com o Relatório de Gestão do Consórcio do ano de 2011 (Consórcio Intermunicipal do Grande $A B C, 2012)$, a definição da agenda de prioridades teve dois importantes desdobramentos políticos: a entrega da Carta do ABC e a apresentação da Agenda Metropolitana.

A Carta do ABC conteve dez pontos considerados estratégicos pela Assembleia dos Prefeitos, e a Agenda Metropolitana do Grande ABC foi o resultado de um encontro com a participação de 18 secretários estaduais e do governador Geraldo Alckmin para anúncio de investimentos do governo estadual na região. A Agenda foi definida pelo Consórcio em amplo debate com os prefeitos e entregue em ordem de prioridade ao governo estadual.

Outro acontecimento importante para o Consórcio foi a construção do Planejamento Estratégico 2011-2020, conforme o documento Consórcio Intermunicipal do Grande ABC (2010), desenvolvido com base nos trabalhos realizados pelos GTs e colocados em uma perspectiva de médio e longo prazo das ações que eram prioridade para a região (entrevista 7).

Dentre as prioridades, a mobilidade urbana ganha relevância na medida em que os presidentes da Assembleia de Prefeitos reiteram a necessidade de se elaborar estudos, fazer análises e desenvolver propostas para os diversos problemas existentes na 
região relacionados a este assunto. Pensar a questão da mobilidade de forma regionalizada foi um dos princípios norteadores que levou o Consórcio a investir em um plano regional que considerasse a interlocução espacial existente entre os sete municípios, e para que, a partir desse âmbito macro, os municípios pudessem detalhar os seus próprios planos locais de mobilidade urbana.

A partir de então, ao mesmo tempo em que ações específicas sobre trânsito e transporte público que afetavam os sete municípios continuavam a ter espaço na agenda do GT Mobilidade, o Consórcio iniciava os estudos para a contratação de uma consultoria para a construção do Plano Regional de Mobilidade (PRM).

O PRM foi financiado em parte pelo próprio Consórcio (R\$ 200 mil) e em parte pela Secretaria de Desenvolvimento Econômico do governo estadual (R \$ 800 mil), e teve como objetivo propor políticas e ações regionais de mobilidade urbana que subsidiassem ações e projetos comuns ou integrados entre os sete municípios do Grande ABC, tendo como principais diretrizes, conforme Consórcio Intermunicipal do Grande ABC (2012):

1. Reorganização das redes municipais e metropolitanas de transporte coletivo;

2. Propor intervenções físicas em obras de ampliação da infraestrutura viária;

3. Estruturar medidas gerenciais ou operacionais de gestão da circulação; e

4. Promover ações de fortalecimento dos órgãos gestores municipais.
A cooperação intermunicipal para a definição de políticas a serem desenvolvidas foi um desafio constante colocado ao Consórcio nas reuniões do grupo técnico e também na Assembleia dos Prefeitos.

\section{Participação e cooperação}

intermunicipal no GT Mobilidade

Apesar do passado histórico semelhante, percebe-se que a participação na elaboração de ações para a mobilidade regional possui um desequilíbrio entre os municípios.

Primeiramente, esse desequilíbrio de atuação dos municípios fica evidente quando analisamos a participação de cada ente nas reuniões do GT Mobilidade, como demonstrado na Tabela 1. Dentro do período analisado, foi possível constatar o baixíssimo envolvimento do município de Rio Grande da Serra, que praticamente não compareceu às reuniões. Na entrevista 4, ficou claro que há relevante diferença de capacidades institucionais entre os municípios, e esta se reflete na cooperação para o planejamento e discussão de projetos de mobilidade. É citado ainda que a prefeitura de Rio Grande da Serra não possui uma secretaria específica para a questão do trânsito e da mobilidade, mas sim uma Divisão de Transportes dentro de Secretaria de Obras e Planejamento.

Essa mesma percepção foi possível captar na entrevista 2 e, de qualquer forma, a baixa participação de Rio Grande da Serra nas reuniões do GT não impedia o desenvolvimento das discussões e das ações realizadas no grupo. Essa dinâmica pode ser entendida em razão

Tabela 1 - Participação (\%) dos municípios nas reuniões do GT Mobilidade entre 2010 e 2013

\begin{tabular}{ccccc}
\hline Ano & $\mathbf{2 0 1 0}$ & $\mathbf{2 0 1 1}$ & $\mathbf{2 0 1 2}$ & $\mathbf{2 0 1 3}$ \\
\hline Município & 58 & 95 & 71 & 95 \\
Diadema & 75 & 74 & 53 & 74 \\
Mauá & 92 & 63 & 75 & 63 \\
Ribeirão Pires & 0 & 0 & 7 & 0 \\
Rio Grande da Serra & 100 & 100 & 96 & 100 \\
Santo André & 100 & 100 & 100 & 100 \\
São Bernardo do Campo & 58 & 63 & 78 & 63 \\
São Caetano do Sul & & & & \\
\hline
\end{tabular}

Fonte: Atas das reuniões do GT Mobilidade do Consórcio Intermunicipal Grande ABC entre os anos de 2010 e 2013. 
do baixo impacto que as questões relacionadas à mobilidade urbana tinham sobre esse município.

Outro entrevistado (entrevista 8) confirmou a baixa participação do município de Rio Grande da Serra nas reuniões do GT Mobilidade, excetuando os encontros relacionados a discussões sobre os projetos advindos do Plano Regional de Mobilidade. Foi colocada a dificuldade que a secretaria possui em relação à quantidade de servidores para realizarem os trabalhos inerentes às demandas da prefeitura e também aquelas originadas pelas discussões do Consórcio. Por outro lado, o papel deste é exaltado como instituição articuladora de interesses para captação de recursos financeiros para os municípios.

É interessante analisar que a importância da participação no GT Mobilidade no Consórcio apenas se torna factível quando se vislumbra a possibilidade de realizar ações concretas no município de Rio Grande da Serra, ficando a participação para discussões de planejamento no âmbito regional em segundo plano. Frey (2012), ao citar Vainer, procura compreender o que impulsiona as ações de municípios em regiões metropolitanas por meio de cooperação intergovernamental:

[...] a perspectiva de possíveis ganhos individuais em virtude de ações coordenadas impulsiona esses agentes para a cooperação e ação coletiva [grifo nosso], tornando crucial a ampliação da capacidade de articular escalas, de analisar e intervir de modo transescalar (Vainer, 2006, p. 28 apud Frey, 2012, p. 89).

A forma de agir do município de Rio Grande da Serra vai ao encontro da ideia de que pequenos municípios, confrontados com suas condições locais desfavoráveis, sentem-se compelidos e/ou estimulados a cooperar com seus vizinhos para poder resolver problemas comuns (Frey, 2012, p. 98).

Ainda em relação à participação dos municípios do ABC no GT Mobilidade, há, por outro lado, aqueles como Santo André e São Bernardo do Campo, que possuem presença praticamente integral nas reuniões do grupo. Essa participação é caracterizada pela presença de técnicos especializados nos assuntos em pauta, pela infraestrutura que possuem, tanto em equipamentos quanto em recursos humanos, e também pela importância que tais prefeitos vêm dando ao tema de mobilidade urbana.
A maior capacidade institucional dessas prefeituras pode ser medida pelo compartilhamento de equipamentos com outros municípios, por exemplo, o empréstimo de caminhões, de guinchos e também no compartilhamento de agentes de trânsito em horários de pico nas regiões de intersecção viária. É possível ainda destacar, pela análise dos documentos das reuniões do GT Mobilidade, o auxílio que os municípios de Santo André e São Bernardo do Campo concedem àqueles com capacidade institucional insuficiente, seja por meio de seu corpo técnico, seja pelo know how que possuem na área de mobilidade urbana.

Assim, pode-se afirmar que o consórcio vem proporcionando o compartilhamento de informações e de conhecimento sobre políticas públicas entre os municípios que são fundamentais para o entendimento das necessidades regionais e para a concepção de que são necessárias a cooperação e o trabalho conjunto para se obter maiores êxitos tanto na barganha com outros entes federativos como para a efetividade e eficiência na execução das políticas trabalhadas no consórcio. Esse entendimento da necessidade de cooperação é uma construção que se dá ao longo do tempo pelo acúmulo das experiências e do aprendizado do papel do Consórcio para a região. Houve um amadurecimento, ao longo dos anos, sobre as limitações de se exercer ações isoladamente e dos ganhos de se agir regional e integradamente, tendo o Consórcio papel central nesse processo.

0 aumento do corpo técnico do Consórcio também foi um fator de relevante auxílio aos municípios com menores capacidades. 0 crescimento institucional do Consórcio Intermunicipal tem possibilitado a contratação de pessoal capacitado para lidar com as problemáticas da região do $\mathrm{ABC}$, podendo assim dar melhor suporte técnico aos municípios.

Constatou-se também que, além da capacidade técnica, a participação de cada município nos grupos de trabalho está estritamente relacionada à importância que cada prefeito faculta àquela política que está sendo desenvolvida coletivamente. Há prefeitos que indicam servidores para o GT Mobilidade com poder de decisão, enquanto outros enviam pessoas apenas para cumprir um papel formal de participação nas discussões promovidas pelo Consórcio.

Assim como Mário Reali e Luiz Marinho colocaram na agenda regional a mobilidade urbana como política prioritária a ser desenvolvida pelo Consórcio, outros prefeitos viram na perspectiva da construção de 
um planejamento regional uma forma de incluir demandas internas a serem ouvidas pelos governos estadual e federal. Além disso, é possível destacar o relevante papel que Marinho possui na intermediação e negociação de recursos e apoio do governo federal aos projetos desenvolvidos dentro do Consórcio. Em diversas entrevistas, foi citada a importância do papel do prefeito de São Bernardo do Campo na articulação com o governo federal para a obtenção de financiamento e de recursos diretos para a execução de projetos por parte do Consórcio e de obras por parte das prefeituras do ABC.

Fica evidente, aqui, a percepção de que, isoladamente, alguns municípios dificilmente teriam poder de barganha suficiente para conseguirem acesso aos governos estadual e federal para a execução de projetos relacionados à mobilidade urbana. Esse aspecto, observado por Oliveira (2008) no caso do consórcio de saúde de Apiaí, pode ser percebido também neste caso. De qualquer forma, é importante destacar que a colaboração entre os municípios mediada pelo Consórcio possui bases sólidas, construída ao longo dos últimos 20 anos. Por isso, podemos dizer que a governança compartilhada provavelmente teria ocorrido sem recursos federais, mas, sem dúvida, em proporção menor e metas muito mais modestas, já que parte considerável dos recursos advém da estrutura federal, comoda Caixa Econômica Federal.

A atual agenda de ações e políticas desenvolvidas pelo Consórcio Intermunicipal é pautada pelas diretrizes advindas do Planejamento Regional Estratégico realizado em 2010 para o período entre 2011 e 2020. Para a política de mobilidade urbana foram desenvolvidas 20 linhas de ações, que vão desde a questão da integração tarifária até a implantação de um sistema de ferroanel na região.

Ao apresentar o Plano ao Ministério do Planejamento, Orçamento e Gestão em 2013, o Consórcio foi orientado a definir seis eixos prioritários para recebimento de recursos do governo federal em curto prazo, por meio do PAC Mobilidade Urbana. É possível considerar que houve importante papel fomentador e direcionador do governo federal na definição do investimento em determinadas ações. Nesse cenário, de entrada do governo federal com a perspectiva de aporte de recursos financeiros, há a necessidade de se discutir quais projetos seriam apresentados como prioritários para a agenda regional de mobilidade. Com isso, os secretários dos municípios se reuniram com os prefeitos para relacionarem os projetos que primeiramente receberiam os investimentos. A partir disso, cada município apresentou projetos para o que ficou conhecido como Plano de Investimentos (entrevista 4) e, ao contrário do que o Consórcio esperava, o município de Rio Grande da Serra conseguiu apresentar projetos para todas as necessidades que faziam parte do planejamento regional e que lhe afetavam diretamente.

As obras do Plano de Investimentos estão sob a coordenação e gestão dos municípios e, para a segunda etapa, o plano prevê o recebimento de aproximadamente 1,1 bilhão de reais do governo federal. Por outro lado, foi afirmado que o próprio Consórcio recebeu em torno de 26 milhões de reais para gerenciar, pela primeira vez, o desenvolvimento de projetos integrados para a política de mobilidade no ABC (entrevista 4). Essa pode ser vista como uma demonstração importante do papel que o consórcio assumiu regionalmente na condução de políticas públicas de interesse coletivo.

\section{papel do Governo do Estado de São Paulo} na política de mobilidade na região do $A B C$

A política de transporte metropolitano de São Paulo está sob a responsabilidade da Secretaria de Transportes Metropolitanos (STM). Dentre suas atribuições estão a execução da política estadual de transportes urbanos para as regiões metropolitanas, a organização, coordenação, operação e fiscalização do sistema metropolitano de transportes públicos de passageiros e sua infraestrutura viária. O Plano Integrado de Transportes Urbanos (PITU 2025), atual agenda de investimentos em transportes e mobilidade do governo estadual, prevê um cronograma de investimentos em projetos como o aumento da malha metroviária em 110 km (em relação a 2005) até 2025, a modernização e duplicação da malha ferroviária da CPTM. Além disso, há no projeto a implantação do conjunto metro-ferroviário Expresso Aeroporto e Trem de Guarulhos.

Um dos gestores estaduais entrevistados (entrevista 5) afirmou que muitas diretrizes contidas no PITU constituem ações norteadoras para os municípios da RMSP e há, em alguns casos, diálogo direto com qualquer município afetado por alguma ação promovida pela STM. Foi declarado, também, que o governo estadual procura buscar o diálogo com 
os municípios contemplados no PITU, mas que nem sempre é possível "chegar a consensos" sobre as ações, projetos e investimentos realizados pela Secretaria.

Na entrevista 5 foi também observado que os projetos empreendidos pela Secretaria são considerados estruturadores da mobilidade metropolitana e que cabe aos municípios planejar e executar suas propostas locais e regionais de acordo com os planos estaduais. Dessa forma, os sistemas criados pelos municípios se subordinam a esse sistema maior e acabam funcionando como alimentadores do sistema estadual. De acordo com o entrevistado, a infraestrutura de transporte e de mobilidade dos municípios do ABC deve se compatibilizar com as ações e estruturas gerenciadas pelo aparato estadual. Essa postura explicita muito bem a relação estado-municípios na política de mobilidade urbana, segundo a visão do gestor estadual.

Essa concepção de que os municípios da RMSP devem se adequar aos projetos estaduais vem pautando as discussões sobre as ações para mobilidade na região do ABC. 0 evento "Agenda Metropolitana", uma parceria do governo estadual com o Consórcio, representou um pacto de integração de ações entre as duas instituições. Entretanto, poucas foram de fato realizadas pelo governo estadual (entrevistas 4 e 7), e os investimentos previstos tanto no sistema viário quanto no sistema de transporte coletivo não foram realizados pelo governo estadual.

Ainda, há assuntos atrelados à mobilidade urbana na região do $\mathrm{ABC}$ que são prioridade para o Consórcio, mas existem empecilhos por parte do governo estadual em desenvolver soluções para projetos, como é o da integração tarifária (entrevista 4).

Houve avanços em relação à integração dos modais de transporte com a criação do cartão BOM (Bilhete Ônibus Metropolitano), que deve ser implantado nos municípios de toda a RMSP, no corredor de ônibus de São Mateus-Jabaquara e em sua extensão no corredor Diadema-Berrini, no Metrô e na CPTM e em algumas linhas municipais. Mas o trabalho que o Consórcio vem realizando é por uma integração entre os municípios do $\mathrm{ABC}$ com os sistemas de transportes metropolitanos, algo que, como vimos, ainda está em fase de diálogo entre os agentes participantes. Dessa forma, é possível afirmar que a integração entre os modais municipais e os de responsabilidade do governo estadual, mediante o bilhete único, constitui o principal desafio da governança compartilhada em relação à mobilidade urbana na região do $\mathrm{ABC}$.
Tanto questões técnicas, colocadas pelo governo do Estado, quanto questões políticas, demonstradas pelo Consórcio, constituem fatores que influenciam diretamente na execução dessa ação. A criação do cartão BOM é um passo importante para a mobilidade da região, mas insuficiente, já que se destina apenas aos ônibus metropolitanos.

Uma das justificativas para a dificuldade em integrar de forma completa os sistemas de transportes metropolitanos, e dentro deles o da região do $\mathrm{ABC}$, é que as secretarias de transportes da maior parte dos municípios não possuem estrutura e capacidade adequadas, o que, muitas vezes, dificulta a compatibilização das discussões e das ações entre Estado e município (entrevista 6).

A importância da participação do governo estadual nas ações relacionadas à mobilidade urbana regional é reconhecida tanto pela Coordenadora do GT Mobilidade quanto pelo Secretário Executivo do Consórcio. 0 maior desafio colocado por eles não é a falta de diálogo com a STM ou com as empresas geridas pela Secretaria, mas sim evoluir do plano argumentativo para o plano prático.

\section{Grupos de interesse: empresas do ramo automobilístico}

Os documentos explicitam a presença da influência de empresas privadas no direcionamento das ações de trânsito e mobilidade discutidas nessas arenas de negociação. Além disso, pela sua localização entre o porto de Santos e a capital, é natural que alguns municípios do $\mathrm{ABC}$ façam parte da rota do fluxo de mercadorias e também de pessoas.

Levando em consideração esse contexto, ações desenvolvidas pelo Consórcio em relação ao transporte e à mobilidade afetam direta e indiretamente empresas da região e, dessa forma, o GT Mobilidade funciona como arena de negociação entre as empresas e os municípios para as ações de mobilidade.

Assim, constata-se, por exemplo, a influência que a ANFAVEA (Associação Nacional de Fabricantes de Veículos Automotores) e o CIESP (Centro das Indústrias do Estado de São Paulo) tiveram na implantação da ação "Operação Horário de Pico", que representou a restrição temporal do tráfego de caminhões em diversas vias da região do $\mathrm{ABC}$. 
Além dos fabricantes de automóveis, as transportadoras da região também têm encontrado no Consórcio, por meio de diálogo com os prefeitos, a possibilidade de colocar questões relativas à mobilidade que lhes afetem diretamente. Cabe ao presidente da Assembleia, em conjunto com os outros prefeitos, buscar o equilíbrio entre as necessidades das empresas da região e o impacto dessas ações na mobilidade regional.

\section{Sociedade civil organizada}

A análise dos documentos do Consórcio possibilitou encontrar diversos grupos de interlocução com os municípios no campo da mobilidade urbana. A influência de cada grupo depende de fatores como seu poder de veto perante os prefeitos da região, do impacto das ações desenvolvidas pelo GT Mobilidade e os limites jurídicos e normativos.

Um tema recorrentemente debatido nas reuniões do GT Mobilidade refere-se ao reajuste da tarifa cobrada pelos taxistas da região. É interessante notar que o Sindicato dos Taxistas reconhece no Consórcio, ao levar anualmente uma proposta de reajustes, uma instituição legítima, aberta ao diálogo e debate acerca dessas solicitações. O Consórcio não tem o poder de fixar parâmetros para o reajuste de tarifas de táxi, mas as propostas são debatidas pelos prefeitos dos sete municípios com o intuito de regionalizar os índices e, entrando em acordo com o sindicato, posteriormente são publicadas em Diário Oficial de cada prefeitura da região.

Além da participação de sindicatos na discussão de ações e políticas voltadas ao transporte e mobilidade, o Consórcio teve a participação da Federação Paulista de Ciclismo (FPC) no debate sobre a criação de uma ciclofaixa de lazer regional no ABC. Em 2012, o Consórcio recebeu representantes da FPC, responsáveis pelo projeto ciclofaixa no município de São Paulo, para apresentação sobre a implantação de um projeto semelhante na região do $\mathrm{ABC}$. Este visava interligar os principais pontos das cidades do Grande $\mathrm{ABC}$ por meio da construção da ciclofaixa, além da disponibilização de bicicletas para locação. Foi criado um grupo de trabalho específico para a elaboração de um projeto regional, ficando a cargo dos municípios a avaliação sobre a capacidade interna de execução da proposta. A incapacidade de parte das prefeituras de trabalhar as questões técnicas pertinentes ao projeto resultou numa estagnação das discussões, que foram suspensas e o GT desmobilizado.

\section{Considerações finais: a Cooperação Intermunicipal no $\mathrm{ABC}$ e a política de mobilidade urbana}

Ao analisarmos a trajetória que o Consórcio Intermunicipal do $\mathrm{ABC}$ desenvolveu ao longo dos últimos anos para a política de mobilidade regional, percebeu-se que houve uma evolução no sentido da integração e cooperação, tanto intermunicipal quanto com outros entes federativos.

Marcada inicialmente por ações isoladas, com projetos pontuais e muitas vezes sem levar em consideração a região como um todo, os municípios do $\mathrm{ABC}$ passaram a promover, por meio do Grupo de Trabalho Mobilidade, ações de forma cooperada, considerando as limitações institucionais de cada prefeitura e também prezando pelas características individuais e necessidades de municípios menores, como é o caso de Rio Grande da Serra. Além disso, o Consórcio amadureceu a condição de articulador regional perante os governos estadual e federal, conseguindo, assim, recursos para projetos diversos, mas principalmente para a política de mobilidade urbana.

Dois casos podem ser retomados como exemplo: um caso de sucesso refere-se à construção do Plano Regional de Mobilidade, em que a região do $A B C$ foi considerada coletivamente para as ações e investimentos em mobilidade urbana e, mais tarde, a obtenção de recursos para o seu financiamento. Em sentido oposto, temos o caso das ciclofaixas, para o qual o Consórcio tentou dar início a uma articulação em favor dessa política pública, mas a falta de capacidade e/ou interesse dos municípios fez com que as discussões e ações não evoluíssem. Isso mostra que a atuação do Consórcio é de fato efetiva, mas depende do envolvimento das prefeituras nos temas em questão. Quando a prioridade é baixa, a presença do Consórcio como aglutinador é insuficiente. Quando ela é alta, a presença pode não ser suficiente, mas é um fator potencializador, que facilita a interlocução federativa, tanto horizontalmente, entre municípios, quanto verticalmente, entre distintos entes federativos.

Ainda há grandes obstáculos a serem trabalhados pelo GT, estes que contribuiriam para uma maior cooperação do governo estadual em questões como 
a integração tarifária dos transportes metropolitanos com os serviços de transporte municipais. Além da integração tarifária, o Consórcio deve acompanhar e cobrar a efetivação das pautas acordadas com o governo estadual, como a Agenda Metropolitana, para que as ações não fiquem apenas no plano do discurso. Os investimentos relacionados à mobilidade urbana constituem-se de ações de médio e longo prazo, e problemas na articulação dos municípios com o governo estadual podem acarretar sérias dificuldades no cumprimento das metas da agenda de investimentos. A compatibilidade entre as propostas e o diálogo frequente são aspectos essenciais que os municípios, mediante o Consórcio, e o governo estadual devem perseguir para que a política de mobilidade regional do $\mathrm{ABC}$ contribua positivamente para a melhora da qualidade de vida dos cidadãos que moram e circulam pela região.

O Consórcio deverá trabalhar também para ajustar o desequilíbrio gerado pelas diferenças de capacidade institucional das prefeituras no desenvolvimento de ações para a mobilidade urbana. Nesse contexto, é possível apontar que a participação de forma cooperada de Rio Grande da Serra, menor município da região do $\mathrm{ABC}$, é impulsionada pela perspectiva de obter recursos para a execução de projetos de mobilidade urbana. Esse fato está em acordo com o que assinalam Abrucio et al. (2010) sobre a necessidade de se criar incentivos para que municípios invistam em ações coordenadas, participando de forma cooperada para o planejamento regional.

Outro importante desafio se relaciona com a execução do Plano Regional de Mobilidade, que deverá exigir, tanto por parte do Consórcio quanto dos sete municípios, empenho para que os investimentos sejam concretizados para a melhoria da mobilidade não só em cada município, mas, principalmente, em toda a região do $\mathrm{ABC}$.

Enfim, pode-se concluir que o Consórcio Intermunicipal Grande $\mathrm{ABC}$ vem desenvolvendo ações para a mobilidade urbana, levando em consideração as especificidades da região do ABC como um todo. Por meio da criação do Plano Regional de Mobilidade, o Consórcio implementa uma política integrada e que contempla, na medida do possível, as necessidades e limitações de cada município. As ações desenvolvidas em conjunto têm maior impacto nas negociações junto aos governos estadual e federal. Além disso, mesmo com as dificuldades encontradas na articulação com o governo estadual, a atuação dos municípios por meio do Consórcio significou um aumento do poder de barganha nessa relação interfederativa.

\section{Agradecimentos}

Agradecemos imensamente os comentários e sugestões dos professores Fernando Luiz Abrucio e Jeroen Klink, participantes da banca de defesa da dissertação, contribuindo para a origem deste artigo. Também agradecemos aos pareceristas anônimos, pelas valiosas sugestões para o aprimoramento da versão final.

\section{Referências}

Abrucio, F., Sano, H., \& Sydow, C. (2010). Radiografia do associativismo territorial brasileiro: tendências, desafios e impactos sobre as regiões metropolitanas. In F. Magalhães (Ed.), Regiões metropolitanas no Brasil (pp. 197-234). Washington: BID.

Brasil. (1973). Lei Complementarnoำ14, de 8 de junho de 1973. Dispõe sobre o estabelecimento das regiões metropolitanas de São Paulo, Belo Horizonte, Porto Alegre, Recife, Salvador, Curitiba, Belém e Fortaleza. Brasília: Diário Oficial da União. Recuperado em 10 de julho de 2014, de http://www.planalto. gov.br/ccivil_03/leis/LCP/Lcp14.htm

Brasil. (1974). Lei Complementar no 20, de 1 de julho de 1974. Dispõe sobre a criação de Estados e Territórios. Brasília: Diário Oficial da União. Recuperado em 10 de julho de 2014, dehttp://www.planalto.gov.br/ccivil_03/leis/LCP/Lcp20.htm

Brasil. (1988). Constituição da República Federativa do Brasil de 1988. Brasília: Diário Oficial da União. Recuperado em 14 de agosto de 2014, de http://www.planalto.gov.br/ccivil_03/ constituicao/constituicao.htm

Brasil. (2012). Lei no 12.587, de 3 de janeiro de 2012. Dispões sobre a instituição das diretrizes da Política Nacional de Mobilidade Urbana; revoga dispositivos dos Decretos-Leis nos 3.326, de 3 de junho de 1941, e 5.405, de 13 de abril de 1943, da Consolidação das Leis do Trabalho (CLT), aprovada pelo Decreto-Lei no 5.452, de 1 o de maio de 1943, e das Leis nos 5.917, de 10 de setembro de 1973, e 6.261, de 14 de novembro de 1975; e dá outras providências. Brasília: Diário Oficial da União. Recuperado em 28 de agosto de 
2014, de http://www.planalto.gov.br/ccivil_03/_ato20112014/2012/lei/112587.htm

Brasil. (2015). Lei no 13.089, de 12 de janeiro de 2015. Dispõe sobre a instituição do Estatuto da Metrópole, altera a Lei no 10.257, de 10 de julho de 2001, e dá outras providências. Brasília: Diário Oficial da União. Recuperado em 18 de agosto de 2014, de http://www.planalto.gov.br/ccivil_03/_Ato20152018/2015/Lei/L13089.htm

Caldas, E. L. (2007). Formação de agendas governamentais local: o caso dos consórcios intermunicipais (Tese de doutorado). Faculdade de Filosofia, Letras e Ciências Humanas, Universidade de São Paulo, São Paulo.

Consórcio Intermunicipal do Grande ABC. (2010). 20 anos planejando e executando ações regionais. Recuperado em 18 de agosto de 2014, de http://www.consorcioabc.sp.gov.br/ imagens/pagina/Revista\%20Planejamento\%20Estrategico\%20 -\%20Consorcio\%20Intermunicipal\%20Grande\%20ABC.pdf

Consórcio Intermunicipal do Grande ABC. (2012). Relatório de Gestão 2011. São Paulo. Recuperado em 14 de agosto de 2014, de http://www.consorcioabc.sp.gov.br/documentos/ relatorio-de-gestao-2011/RelatoriodeGestao2011.pdf

Consórcio Intermunicipal do Grande ABC. (2014). Grupos de Trabalho. São Paulo. Recuperado em 15 de janeiro de 2014, dehttp://www.consorcioabc.sp.gov.br/grupos-de-trabalho/ eixo-infraestrutura

Cruz, M. C., \& Araújo, F. F. (2011). Consórcios intermunicipais paulistas rumo aos consórcios públicos: reflexões. Fundação Prefeito Faria Lima. São Paulo: Cepam. Recuperado em maio de 2014, de http://repositorio.fjp.mg.gov.br/consad/ bitstream/123456789/520/1/C4_TP_CONS\%C3\%93RCIOS\%20 INTERMUNICIPAIS\%20PAULISTAS\%20RUMO.PDF.pdf

Cruz, M. F. (2010). Condicionantes metropolitanos para políticas públicas: análise dos transportes coletivos na Região Metropolitana de São Paulo (1999-2009) (Dissertação de mestrado). Fundação Getúlio Vargas, São Paulo.

Cunha, J. M. P., Stoco, S., Dota, E. M., Negreiros, R., \& Miranda, Z. A. (2013). A mobilidade pendular da Macrometrópole Paulista: diferenciação e complementaridade socioespacial. Cadernos Metrópole, 15(30), 433-459. http://dx.doi. org/10.1590/2236-9996.2013-3004.

Fernandes, A. S. A., \& Araújo, S. M. V. G. (2015). A criação dos municípios e a formalização das regiões metropolitanas: os desafios da coordenação federativa. urbe. Urbe. Revista
Brasileira de Gestão Urbana, 7(3), 295-309. http://dx.doi. org/10.1590/2175-3369.007.003.A007.

Frey, K. (2012). Abordagens de governança em áreas metropolitanas da América Latina: avanços e entraves. Urbe. Revista Brasileira de Gestão Urbana, 4(1), 87-102. http:// dx.doi.org/10.1590/S2175-33692012000100007.

Instituto Brasileiro de Geografia e Estatística - IBGE. (2015). Pesquisa de informações básicas municipais: perfil dos municípios brasileiros. Brasília. Recuperado em 15 de janeiro de 2014, de http://www.ibge.gov.br/home/estatistica/economia/ perfilmunic/2015/

Klink, J. J. (2005). Perspectivas recientes sobre la organización metropolitana: funciones y governabilidade. In E. Rojas, J. R. Cuadrado-Roura, \& J. M. F. Guell (Eds.), Gobernar las metrópoles (pp. 127-191). Washington: Banco Interamericano de Desarrollo, Universidad de Alcalá de Henares.

Lacerda, N., Mendes Zancheti, S., \& Diniz, F. (2000). Planejamento metropolitano: uma proposta de conservação urbana e territorial. Revista Latinoamericana de Estudios Urbano Regionales, 26(79), 77-94.

Oliveira, V. E. (2008). Municípios cooperando com municípios: relações federativas e consórcios intermunicipais de saúde no estado de São Paulo. São Paulo em Perspectiva, 22(1), 107-122.

Pero, V., \& Stefanelli, V. (2015). A questão da mobilidade urbana nas metrópoles brasileiras. Revista de Economia Contemporânea, 19(3), 366-402. http://dx.doi.org/10.1590/198055271932.

Santos, M. (1993). A urbanização brasileira. São Paulo: Hucitec. 173 p.

Souza, C. (2003). Regiões Metropolitanas: condicionantes do Regime Político. Lua Nova, (59), 137-158. http://dx.doi. org/10.1590/S0102-64452003000200007.

Spink, P. K., Teixeira, M. A. C., \& Clemente, R. (2009). Governança, governo ou gestão: o caminho das ações metropolitanas. Cadernos Metrópole, 11(22), 453-476.

Tribunal de Contas da União - TCU. (2010). Relatório e Parecer Prévio sobre as Contas do Governo da República. Brasília. Recuperado em 10 junho de 2014, de http://portal.tcu.gov. br/tcu/paginas/contas_governo/contas_2010/index.html

Recebido: Ago. 26, 2016

Aprovado: Fev. 12, 2017 